\title{
Experimental Study on Gas Slippage of Tight Gas Sands in Kirthar Fold Belt Sindh, Pakistan
}

\author{
AFTAB AHMED MAHESAR*, ABDUL MAJEED SHAR**, KHALIL REHMAN MEMON*, \\ HAFEEZ-UR-RAHMAN MEMON*, AND SHAHZAD ALI BALADI* \\ RECEIVED ON 17.11.2016 ACCEPTED ON 21.02.2017
}

\begin{abstract}
The laboratory experiments on samples from Kirthar fold belt of lower Indus basin Sindh Pakistan were carried out to investigate the effect of gas slippage under varying conditions of pore pressures and overburden stress. The samples were dried in an oven at temperature of $60^{\circ} \mathrm{C}$ and were randomly selected for measurement of permeability and porosity. Permeability was measured using nitrogen gas, while the porosity measurements were made using helium gas expansion porosimeter. The bulk volume was determined by measuring sample diameter and length with caliper. The permeability results suggest that gas slippage increases as if low pore pressures are used, which leads to higher measured permeability than intrinsic permeability of samples. An attempt was also made to estimate the permeability using existing correlations and found that there is large scatter in predicted permeability and measured data. This large amount of scatter in the predicted permeability values concludes that unless absolutely necessary, such correlations should not be used where accurate absolute permeability values are needed. Moreover, the permeability and porosity were plotted together to develop a relation between two properties; the power law fitting of the data well explains the relation between permeability and effective porosity.
\end{abstract}

Key Words: Klinkenberg Effect, Tight Gas Sands, Slippage Phenomena.

\section{INTRODUCTION}

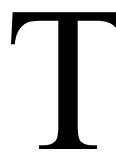

light rock formations are important in many ways either to produce the gas, oil, to meet the energy needs or to store the $\mathrm{CO}_{2}$ and nuclear wastes into underground earth, as these rocks exhibits extremely low permeability $[1,2]$. Hence, it is essential to characterise the flow of gas within such tight rock formation having very small pore throats and the changes, which might occur within their permeability due to pore pressures and overburden stresses changes that need to be examined. In assessment of oil and gas reservoir production performance accurate permeability values are essential. Usually, the gas is used as the flowing fluid to perform laboratory experiments to measure the rock permeability of tight rocks [3].Tight

* Institute of Petroleum \& Natural Gas Engineering, Mehran University of Engineering \& Technology, Jamshoro.

** Department of Petroleum Engineering, NED University of Engineering \& Technology, Karachi.

Mehran University Research Journal of Engineering \& Technology, Volume 36, No. 3, July, 2017 [p-ISSN: 0254-7821, e-ISSN: 2413-7219] 
rocks having compacted pore structure, dense pore network, and flow pathways are very small, so the mean free path of the molecules of gas changes considerably compared totheirpore-throat radius. It also have been reported that if mean free path of the gas molecules is higher in the magnitude of order two of the diameter of pore throats there will be possibility of molecules slippage on the pore surfaces. Hence, this deviates from obeying Darcy's law and the resulting value of permeability will be higher [4].

The gas permeability measurements are generally made using low pore pressures i.e. 100 psi and lower confining stress of about 400 psi. Hence, the permeability measurements conducted at low pore pressures need to be corrected to take into account of gas slippage effects to obtain accurate permeability values.Although, in a low permeability porous medium, the pores with their diameter equal to mean free path of the gas molecules further enhances the gas flow within pore walls i.e. the slippage flow of gas molecules resulting in increased rate of flow of the gas as well as the apparent permeability [5]. Permeability of tight rocks could be measured either by steady-state measurement methods [6] or by pressure pulsetransient method $[7,8]$. Steady-state measurements are extensively used to measure the gas slippage effects apart from permeability of porous rocks. Several authors conducted steady-state flow experiments at constant confining pressure and constant net confining pressures $[6,9,10]$. Steady state experiments on low permeability samples however are expensive and time consuming. Further that pulse-decay method for permeability measurement of tight rocks is based on unsteady-state flow mechanism [1], which is less expensive and less time consuming. However, in petroleum industry single permeability measurement is conducted at a low gas pore pressures, and then corrected for Klinkenberg effect to get the gas slippage factor values. Gas slippage factor values are then used to relate with permeability or with porosity and permeability $[11,12]$ and furthermore the rock is a group of cylindrical pores, and their permeability is directly related to pore radius such as, $\mathrm{k}_{,} \propto \mathrm{r}^{4}$, hence slippage radius obtained from slippage parameters could be related with permeability asr slip $_{1} \propto(\mathrm{k}, / \phi)^{1 / 2}$ and or $\mathrm{b} \propto\left(\mathrm{K}_{,} / \phi^{-}\right.$ 0.5 ) [13]. The slippage (b) factor in the above equation could be influenced by the type of gasused during the measurements; hence the correlations need to be modified for the individual gas used [14]. However, [10] further reported that permeability measured with the same gas has also resulted in a significant scatter when plotted against slippage factor values. Therefore, this raises uncertainty while implementing such correlations to make data equivalent to in-situ conditions and may result in error in estimating theslippagefactor values. Hence, to save the time, and hence the operational costs for permeability measurement of tight rock under in situ conditions, transient techniques such as pulse decay permeametry is being practiced by the industry $[1,8,11]$. The pulse-decay permeability experiments are performed using high pore pressures gas, usually more than 2000 psi [15]. Permeability measured using higher pore pressures will result in lower gas slippage effect [15], however, it is still recommended to perform the Klinkenberg corrections to achieve the slippage corrected absolute gas permeability data [15]. Though, the core laboratories use theoretical [5] or empirical relationships between permeability and slippage to correct data collected at low pressures [4]. Which is not appropriate to account for accuracy rather it would be far better to measure the permeability and obtain slippage corrected permeability in the laboratory. 
It is perceived that the model of Klinkenberg and its extensions might yet underestimate the role of gas slippage in permeability test data collected by petroleum industry as part of a routine core analysis especially for tight porous media [5-16]. Hence, to check the validity of such assumption a comprehensive study has been conducted and results are reported in the following sections.

\section{GAS FLOW MECHANISM}

The Klinkenbergslip flow model [17] is linearly associated with the measured gas permeability with the inverse of the mean pressure $(1 / \mathrm{Pm})$ and the Klinkenberg $b$-factor. The following equation has been formulated based on the pore pressure correction:

$$
K_{g}=K_{1}\left(1+\frac{b}{P}\right)
$$

Where $\mathrm{k}_{\mathrm{g}}$ is the apparent gas permeability, $\mathrm{k}_{1}$ is the equivalent liquid permeability; $\mathrm{b}$ is the Klinkenberg slip factor parameter and $\overline{\mathrm{P}}$ is the average pressure recorded during the flow experiments. Flow tests would be conducted at different levels of pore pressures and then a plot of apparent gas permeability vs $1 / \mathrm{p}$ constructed then be extrapolated to $1 / p=0$ [17]. The permeability obtained from the Klinkenberg tests can then be fitted with using a straight line to estimate the (b-factor slippage parameter, as per recommendations made by the API (1998). Only those data points could be fitted to a straight line which have a correlation coefficient greater than 0.96 and it is recommended that at least four or more data points are required as shown in Fig. 1. It is also theoretically possible to get pore radius from b-factor values using following Equation (2) of (Klinkenberg [17]):

$$
b=\frac{r c \lambda P}{r_{e f f}}
$$

Where $\mathrm{c}$ is dimensionless parameter that depends on the geometry but is in the order of one (Klinkenberg [17]). The $\mathrm{b}$ factor is constant with pore pressure (Klinkenberg [17]), in that the $\lambda$ is expressed as in Loeb[34].

$$
\lambda=\frac{\mu}{P_{p}} \sqrt{\frac{R T \pi}{2 M}}
$$

Where $\mu$ is the gas viscosity, $\mathrm{R}$ the gas constant, $\mathrm{T}$ absolute temperature, and $\mathrm{M}$ the molar mass of the gas.

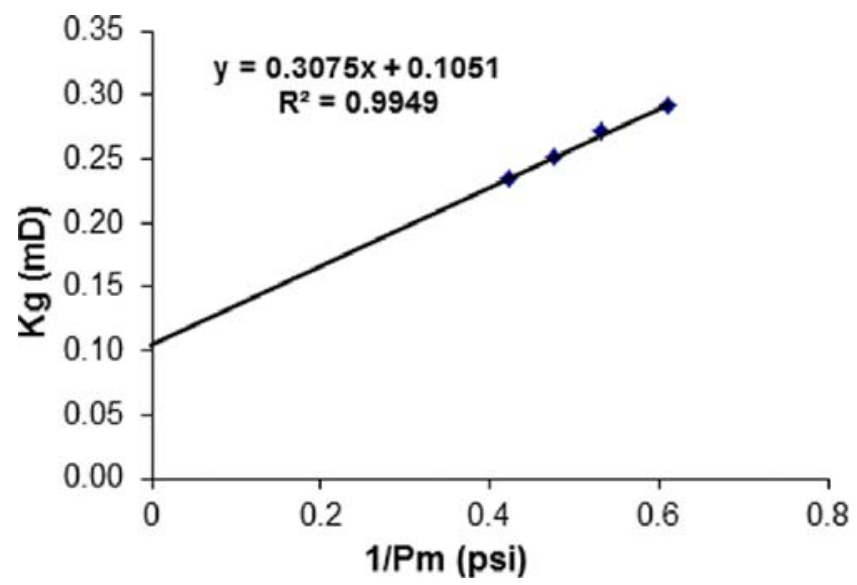

FIG. 1. DIAGRAMS SHOWING THE PRINCIPLE BEHIND KLINKENBERG CORRECTIONS 
The gas slippage-factor entirely depends upon the size of the pore; hence, the different rocks have different value of gas slippage factor, which varies with type of rock. The b-factor has remained focus of various investigators within the oil and gas industry to derive a relation with permeability to estimate effective liquid permeability $K_{L}[12,13,16,18,19]$. Therefore, there are a number of correlations (i.e. empirical and theoretical) are available in literature those relate slip factor to porosity, permeability and tortuosity $[7,11,20]$. A summary of the existing slippage factor correlations have beenprovided in Table 1.

Different flow regimes could be related with different Knudsen numbers, these are associated to the Knudsen number values $[4,5]$, such as the continuum flow, slip flow, transitional flow and free molecular flow.A relation of Knudsen number as a function of pressure with varying pore sizes ranging from $5 \mathrm{~mm}$ to $1 \mathrm{~nm}$. The slippage due to gas molecules occurs in the condition when, gas molecule's mean free path results in similar to pore throat radius $(0.001<\mathrm{Kn}<0.1)$. In these conditions the molecules of gas gets slipped on the inner surfaces of the pores resulting in higher apparently permeability than the absolute permeability liquid permeability measured using a liquid as a pore fluid [7].

\section{GEOLOGY OF KIRTHAR FOLD BELT}

The samples collection location as specified in Fig. 2 and is represented as Kirthar Fold Belt which is located in (West Pakistan Fold Belt) [22]. This location provided a good reservoir formation and is realized to have good potential of hydrocarbon reserves as well as having good trapping mechanism [23-24]. Pab formation in Kirthar Fold Belt is a sedimentary rock; this comprises the thick marine siliciclasticpab formations and is ranging from $50-450 \mathrm{~m}$. Kirthar fold belt pab sedimentary formation is composed of sandstone rocks, which are interbedded with marl and

TABLE 1. SUMMARY OF THE EXISTING SLIPPAGE FACTOR CORRELATIONS

\begin{tabular}{|c|c|c|c|}
\hline No. & Author & Comments & Model Equation \\
\hline 1. & Klinkenberg [17] & Air was used and $\mathrm{C} \sim 1$ & $\mathrm{~b}=4 \mathrm{cP} / \mathrm{r}$ \\
\hline 2. & Heid et. al.[11] & $\begin{array}{c}\text { The core samples from different were used for permeability measurements and } \\
\text { values of permeability were in range of } 0.1-1000 \mathrm{mD}\end{array}$ & $\mathrm{b}=11.419$ (Kliq) -0.39 \\
\hline 3. & Jones and Owens [12] & Core samples $(>100)$ ranging from $0.01-2500 \mathrm{mD}$ & $\mathrm{b}=12.639$ (Kliq) -0.33 \\
\hline 4. & Jones [2] & Tight gas sand samples ranging from $0.10-100 \mathrm{mD}$ & $\mathrm{b}=6.9$ (Kliq) -0.36 \\
\hline 5. & Sampath and Keighin,[13 ] & Cores obtained from North sea gas reservoir. $(0.01-10 \mathrm{mD})$ & $\mathrm{b}=13.851$ (Kliq) -0.53 \\
\hline 6. & McPhee and Arthur, [21] & Field core samples obtained from tight gas sand (10-15-10-17 m2) & $\mathrm{b}=0.0955(\mathrm{Kliq} /)-0.53$ \\
\hline 7. & $\begin{array}{l}\text { Tanikawa and Shimamoto } \\
{[18]}\end{array}$ & $\begin{array}{l}\text { Sample from sedimentary rock with permeability in range of } 0.001-10 \mathrm{mD} \text { were } \\
\text { used for analysis }\end{array}$ & $\mathrm{b}=11.2$ (Kliq) -0.37 \\
\hline 8. & Florence et. al. [7] & $\begin{array}{l}\text { Collected data from different sources }(0.01-0.01 \mathrm{mD} \text { (literature survey data used } \\
\text { for analysis) }\end{array}$ & $\mathrm{b}=43.345(\mathrm{~K}$ liq $/)-0.5$ \\
\hline 9. & Civan et. al. [20] & Theoretical model accounted pore tortuosity & $\mathrm{b}=0.0094(\mathrm{Kliq} /)-0.5$ \\
\hline 10. & Letham and Bustin [22 ] & Data from the literature and from other sources $(0.01-0.01 \mathrm{mD}$ & $\mathrm{b}=0.026$ (Kliq) -0.43 \\
\hline
\end{tabular}

Mehran University Research Journal of Engineering \& Technology, Volume 36, No. 3, July, 2017 [p-ISSN: 0254-7821, e-ISSN: 2413-7219] 
mudstones associated with other rock formations of limestones [25]. The color of these sands is yellow, grey, light brown and greenish [23]. This Kirthar fold belt rock formation comprises the medium to coarse gained, moderately sorted, and is well rounded to sub rounded. In this Marl present is very thin bedded and is light grey in color and is finely laminated Mudstone is bioturbated and is brownish reported two depositional systems. One is shallow marine and other one is fluviodeltaic to deep marine turbidities [23-24-25].

\section{SAMPLE PREPARATION AND EXPERIMENTAL SET-UP}

Cylindrical plugs of $\sim 35 \mathrm{~mm}$ diameter and $62 \mathrm{~mm}$ length were completely cleaned by a Soxhlet extractor apparatus in the laboratory using a mixture of methanol-toluene and dichloromethane. The samples were dried by placing them in oven at $60^{\circ} \mathrm{C}$ for two days prior to measurements. After that the samples were randomly selected and measurements of permeability and porosity were conducted. For porosity measurement, a helium gas expansion porosimeter was used to determine the grain volume, GV, of the dry samples. The bulk volume, BV, was determined by measuring the sample diameter and length with caliper as well as weighing the water saturated sample when immersed in water using Archimedes principle. The porosity is given by following Equation (4):

$$
\phi=\frac{B V-G V}{B V}
$$

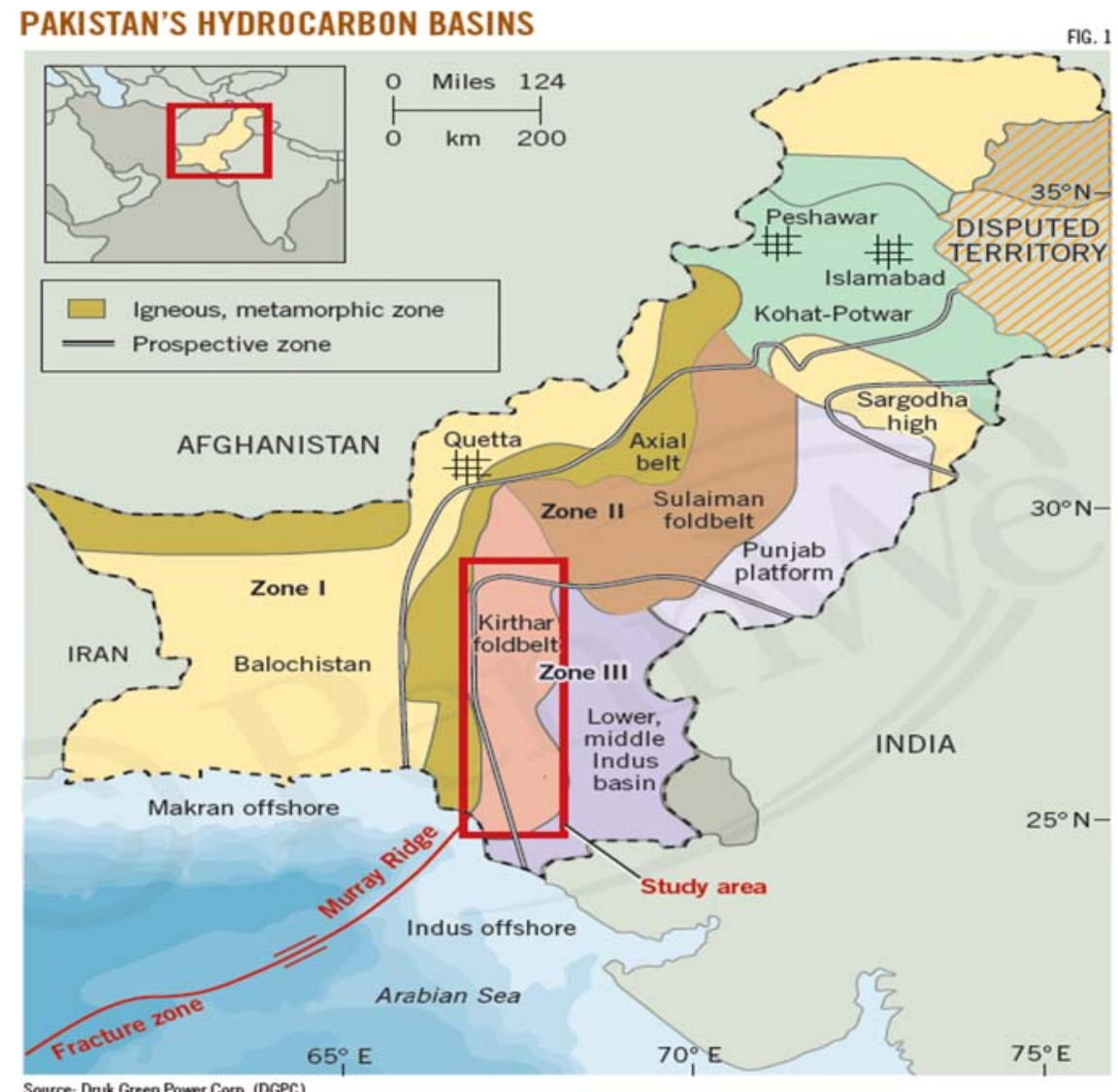

FIG. 2. THE STUDY AREA REPRESENTED IN THIS MAP [24], MODIFIEDFROM DGPC REPORT, 2012) 
The permeability measurements were made by flow of gas across the samples. Both methods wereadapted to measure permeability, steady state [API, 1998] and pulsedecay technique [7]. For the steady-state tests, the apparent permeability is calculated using following equation,

$k_{a}=\frac{2 \mu L_{s} Q_{a} P_{a}}{A_{s}\left(P_{1}^{2}-P_{2}^{2}\right)}$

where $\mu$ is the gas viscosity, $L_{s}$ is the sample length, $Q_{a}$ is the flow rate at ambient pressure $\mathrm{P}_{\mathrm{a}}, \mathrm{A}_{\mathrm{s}}$ is the cross sectional area of the sample, and $\mathrm{P}_{1}$ and $\mathrm{P}_{2}$ are the pressures at the upstream and downstream side of the sample respectively. Transient permeability tests were conducted; and permeability measurements were made at stress up to $70 \mathrm{MPa}$ confining pressure and $55 \mathrm{MPa}$ to prevent the leakage of the permeant (Fig. 3).

\section{EXPERIMENTAL RESULTS AND DISCUSSIONS}

The slippage corrected gas permeability of Kirthar fold belt tight sands were conducted under range of overburden stress and varying pore pressures. The basic samples properties and dimensions and other relevant parameters are listed in Table 2 . The detailed analyses were performed on KBF1 and KBF2 samples. The linear plots of Klinkenberg were constructed by extrapolating the data to inverse of mean pore pressures versus apparent permeability. In all samples, similar effective stress coefficient $\alpha=1$ was considered. The slip-free permeability plots for all samples were plotted as a function of effective stress, which provided a good power law fitting to the measured results (Fig. 4).

\section{CHARACTERISTICS OF GAS FLOW IN TIGHT GAS SANDS}

The experimental methodology was used for tight rock sample's gas permeability measurement under different confining stresses and different pore pressure conditions.

TABLE 2. BASIC PHYSICAL PARAMETERS AND DIMENSIONS OF THE SAMPLES FROM KIRTHAR FOLD BELT

\begin{tabular}{|c|c|c|c|c|c|}
\hline No. & Sample ID & $\begin{array}{c}\text { Diameter } \\
(\mathrm{cm})\end{array}$ & $\begin{array}{c}\text { Length } \\
(\mathrm{cm})\end{array}$ & $\begin{array}{c}\text { Porosity } \\
(\%)\end{array}$ & $\begin{array}{c}\text { Density } \\
(\mathrm{gr} / \mathrm{cc})\end{array}$ \\
\hline 1. & KFB1 & 2.21 & 5.8 & 7.5 & 2.55 \\
\hline 2. & KFB2 & 2.54 & 6.2 & 3.8 & 2.56 \\
\hline 3. & KFB3 & 2.52 & 6.2 & 3.2 & 2.62 \\
\hline 4. & KFB4 & 2.55 & 6.0 & 4.5 & 2.57 \\
\hline
\end{tabular}

2

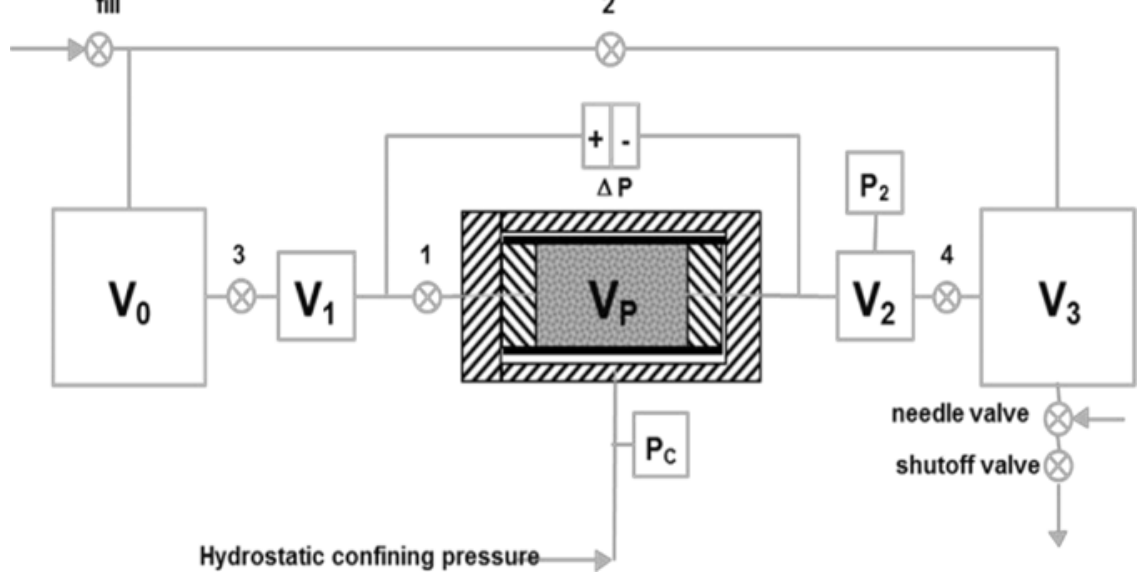

FIG. 3. PULSE-DECAY APPARATUS FOR UNSTEADY-STATE PERMEABILITY MEASUREMENT TO GAS (TAKEN FROM CORE LABS INSTRUMENTS) 
Figs. 5-6 provides results for four specimen tested, these figures provides the relations in between the pressure difference square and gasf low rate Qs (Figs. 5-6) for specimens studied (KFB1 and KFB2) listed in Table 2.

It can be observed from plots (Figs. 5-6) at varying gas pore pressures and constant overburden stress, the gas flow and pressure drop square relation follows the nonlinear behaviour in our experiments as explained in Equation (5) these should follow linear relation. Instead, the curves should follow linear trend, conversely the plots have shown downward deviation and are convex, particularly for the experimental conditions using low pore pressure and higher overburden stress. Hence, this shows that the tight rock samples in Kirthar formation are affected by the Klinkenberg slippage flow effects. Moreover, the experiments conducted on tight formations of granite by Baehr and Hult [26] also have reported that the flow of gas within granite tight formations have shown significant Klinkenberg effects. Other studies [17] also reported from their experiment observations that thegas slippage effects cannot be ignoredwithin tight rock formations. Moreover, in [12-13] they reported solutions of different analytical

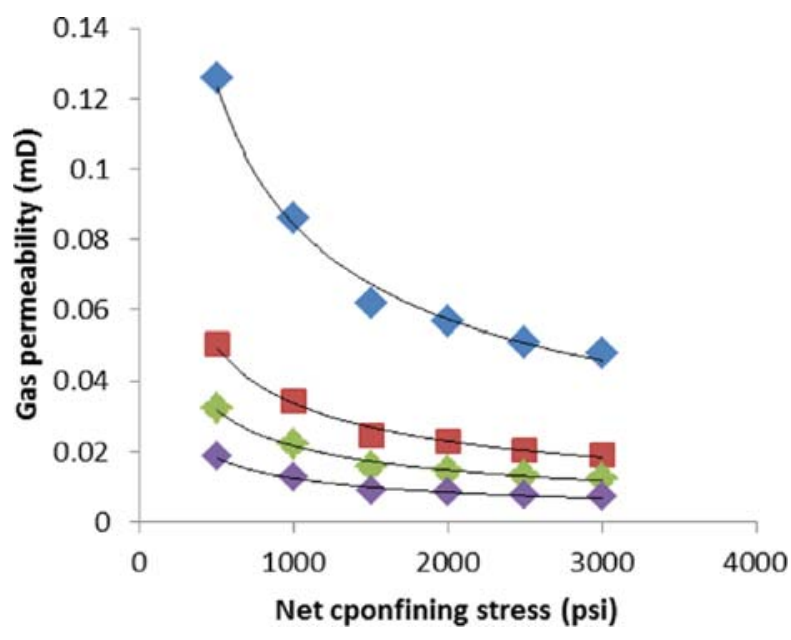

FIG. 4. PERMEABILITY OF KIRTHAR FOLD BELT SAMPLES MEASURED UNDER CHANGING OVERBURDEN STRESSES PLOTTED AS FUNCTION OF NET CONFINING STRESS AND WAS FITTED WITH POWER LAW REGRESSION equations steady state and steady stateflow conditions of gasand found that theslippage effects plays significant role. Results from the current work also reflect that overburden stress, pore pressures and rock pore throat radius cannot be ignored, and these parameters plays significant role to affect the gas slippage especially in low permeability reservoirs. In following subsections of the manuscript we have further discussed the influence of gas slippage within tight formations in Kirthar fold belt basin.

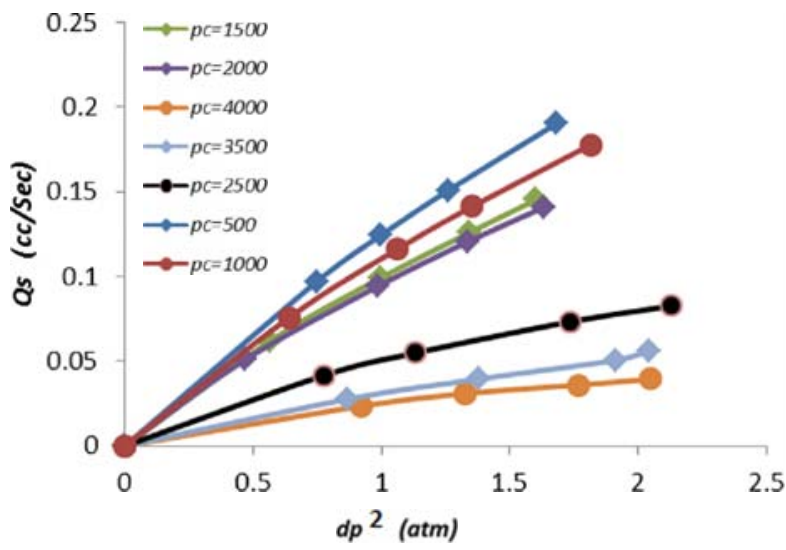

FIG. 5. PLOT IS THE GAS FLOW UNDER CHANGING PORE PRESSURE AT CHANGING OVERBURDEN STRESS IN KFB1 SAMPLE

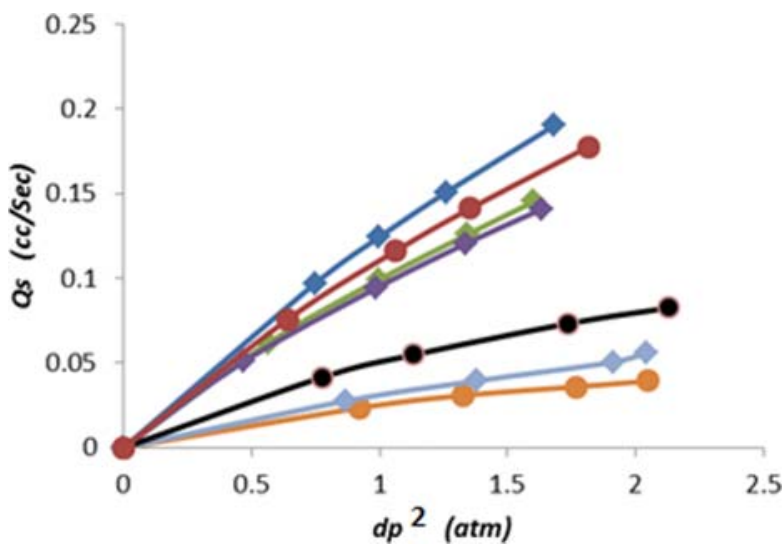

FIG. 6. PLOT IS THE GAS FLOW UNDER CHANGING PORE PRESSURE AT CHANGING OVERBURDEN STRESS IN KBF2 SAMPLE

Mehran University Research Journal of Engineering \& Technology, Volume 36, No. 3, July, 2017 [p-ISSN: 0254-7821, e-ISSN: 2413-7219] 


\section{INFLUENCE OF PORE PRESSURE ON GAS SLIPPAGE EFFECT}

The Equation (3) describes that if there is increase in mean free path of the gas molecules $(\lambda)$ due to the reduced pore pressure of gas which will result in increased gas slippage effects leading to higher gas permeability (measured) than true permeability of the samples. Moreover, if the mean free path of molecules of gas decreases the gas pore pressure rises and the slippage affects get in reduced values. The permeability data obtained using laboratory facility was plotted against the inverse of mean pore pressure of gas and are shown in Fig. 7 (a-b) for samples KFB1 and KFB2. These results show that there is good relationship between gas permeability and inverse of mean pore pressure and obey the Darcy's law. However, it was seen that the measured

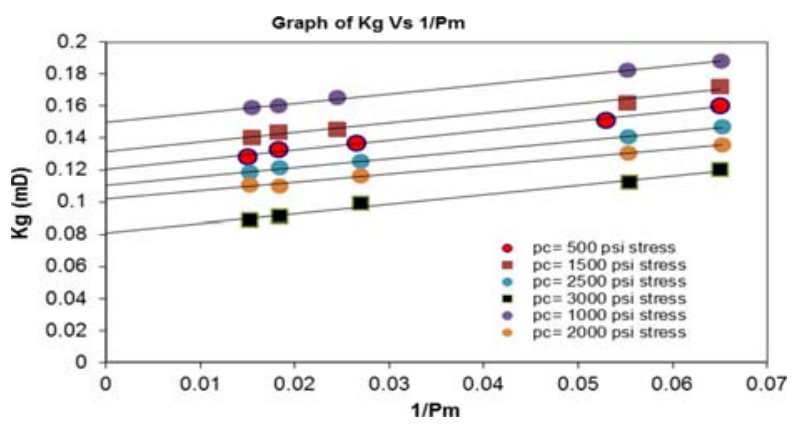

(a)

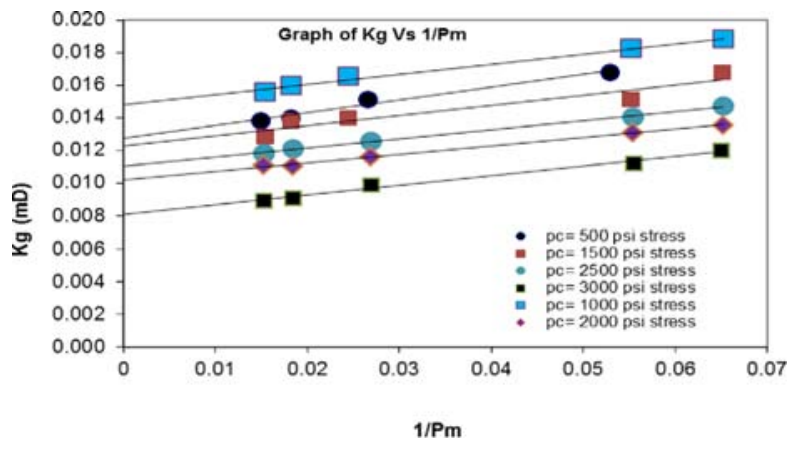

(b)

FIG. 7. KLINKENBERG PLOTS FOR TWO OF THEKIRTHAR FOLD BELT SAMPLE AT DIFFERENT NET EFFECTIVE STRESSES permeability to gas increases at the same overburden stress, by raising the inverse of mean pore pressure $(1 / \mathrm{pm})$. It is often seen that if gas pore pressure is lower i.e. below $<100$ psi, the molecules mean free path will be larger compared to higher pore pressure i.e. $>500 \mathrm{psi}$, so in case of low pore pressure the measured gas permeability will be high. Hence, the Klinkenberg effect shows major role in these low permeability reservoirs and is essential to quantify, and could not be ignored.

The slip-free permeability and slippage (b) factor values can be determined using Equation (1) by extrapolating the permeability to inverse of the mean pore pressure Fig. 7(a-b). The estimated values of slippage factor and permeability for each confining stress are presented in Tables 3-4 respectively. The plotted values of permeability as a function of reciprocal mean of the pore pressure shows good linear relationship and the fitting coefficients were equal to or $>0.98$.

\section{RELATIONSHIP BETWEEN ABSOLUTE PERMEABILITY AND EFFECTIVE POROSITY}

All samples of tight sands of Kirthar fold belt shown a large reduction in permeability due to increase in overburden stress and very small reduction in porosity was noticed. The porosity of sample reduced by two percent due to fractures closing; however, there was around one order of magnitude decrease in permeability due to overburden stress increase.

The porosity measured under different net stresses showed slight reduction; the resulted are presented in Tables 3-4. As the stress increased the absolute permeability in all samples shown decrease, the extent of reduction of permeability was large than the porosity of samples at same confining stress. The permeability as a 
function of porosity is plotted Fig. 8(a-b). The relation of permeability porosity follows a power law regression fitting and is:

$$
K_{g \infty}=K_{g}^{0} \times\left(\frac{\phi}{\phi_{o}}\right)^{n}
$$

TABLE 3. KLINKENBERG LINEAR FITTING REGRESSION RESULTS FOR SAMPLE KFB1

\begin{tabular}{|c|c|c|c|c|}
\hline Confining Stress (psi) & Equation & Porosity (fractions) & $\begin{array}{c}\text { Kg(Slip-Free } \\
\text { Permeability) } \\
\text { (mDarcy) }\end{array}$ & $\begin{array}{c}\mathrm{b} \\
\text { (psi) }\end{array}$ \\
\hline 500 & $K_{g}=1.258\left(1+\frac{0.165}{p m}\right)$ & 8.5 & 0.070 & 8 \\
\hline 1000 & $K_{g}=1.258\left(1+\frac{0.215}{p m}\right)$ & 7.5 & 0.054 \\
\hline 1500 & $K_{g}=1.258\left(1+\frac{0.325}{p m}\right)$ & 6.78 & 50 \\
\hline 2000 & $K_{g}=1.258\left(1+\frac{0.232}{p m}\right)$ & 6.2 & 0.024 \\
\hline 3000 & $K_{g}=1.258\left(1+\frac{0.254}{p m}\right)$ & & 120 \\
\hline
\end{tabular}

TABLE 4. KLINKENBERG LINEAR FITTING REGRESSION RESULTS FOR SAMPLE KFB2.

\begin{tabular}{|c|c|c|c|c|}
\hline Confining Stress (psi) & Equation & Porosity (fractions) & $\begin{array}{c}\mathrm{K}_{\mathrm{g}}(\text { Slip-Free } \\
\text { Permeability) } \\
(\mathrm{mDarcy})\end{array}$ & $\begin{array}{c}\mathrm{b} \\
(\mathrm{psi})\end{array}$ \\
\hline 500 & $K_{g}=1.258\left(1+\frac{0.424}{p m}\right)$ & 5.9 & 0.004 & 195 \\
\hline 1000 & $K_{g}=1.258\left(1+\frac{0.325}{p m}\right)$ & 5.8 & 0.003 \\
\hline 1500 & $K_{g}=1.258\left(1+\frac{0.255}{p m}\right)$ & 5.5 & 189 \\
\hline 2000 & $K_{g}=1.258\left(1+\frac{0.398}{p m}\right)$ & 5.4 & 0.0013 \\
\hline 2500 & $K_{g}=1.258\left(1+\frac{0.523}{p m}\right)$ & 5.12 & 200 \\
\hline
\end{tabular}

Mehran University Research Journal of Engineering \& Technology, Volume 36, No. 3, July, 2017 [p-ISSN: 0254-7821, e-ISSN: 2413-7219] 
Where $K_{g_{\infty}}^{0}$, is the slip-free permeability measured at ambient stress conditions in $\mathrm{m}$ Darcy, $\phi$ is the porosity at initial conditions, and $\mathrm{n}$ is the regression coefficient. The present study data fitted with regression co-efficient is reported in Tables 3-4. After fitting the data with several different correlations as exponential and power law regression coefficient we found that the power fitting was reasonably good compared to Civan et. al. [20]. Our results are consistent with the finding of other authors [20].

\section{RELATIONSHIP BETWEEN ABSOLUTE GAS PERMEABILITY AND SLIPPAGE FACTOR}

It is generally known that for low permeability samples the slippage factor values becomes larger; this means that it is essential to do corrections for low permeability samples otherwise errors could be expected in permeability and the extent of these errors likely become larger as permeability decreases. The results obtained within present study shows that it is essential to either measure b-values for each sample separately. Otherwise it is recommended that alternatively, high gas pore pressures (>1000 psi) should be used so that the Klinkenberg correction becomes negligible for tight gas sandstone reservoirs [5]. Fig. 4 shows the gas slippage b-values measured during the present study and compared to that data presented about Mesaverdetight sands [10]. Three key findings of the data obtained from results are, (i) the b-factor values are related to absolute permeability using the Equation (7):

$$
b=15.097 K_{a b}^{-0.325}
$$

Whereb is in psi and $\mathrm{k}_{\mathrm{ab}}$ in $\mathrm{m}$ Darcy. There appears to be no systematic difference between b-values between tight gas samples from our study and that of Byrnes [10] and (iii) there is around half order of magnitude scatter in measured b-values.

Various correlations are present within the literature (Table 1) to relate the gas slip factor with permeability [7-12-21]. We tested these relationships, for comparing with our data to see the validity of model predictions (Fig. 9). It was found that in Fig. 9 there was a scatter in slip factor values; and was around one order of magnitude. Obviously, the estimation of slippage values

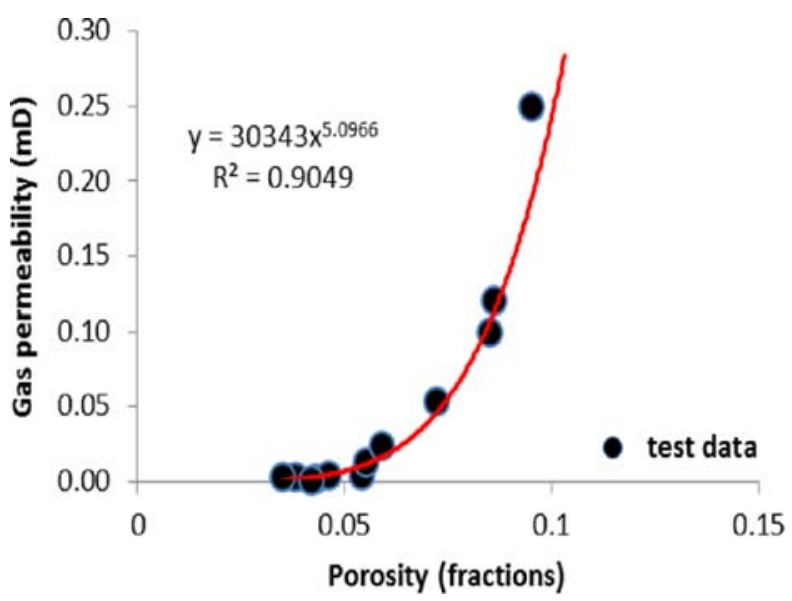

(a)

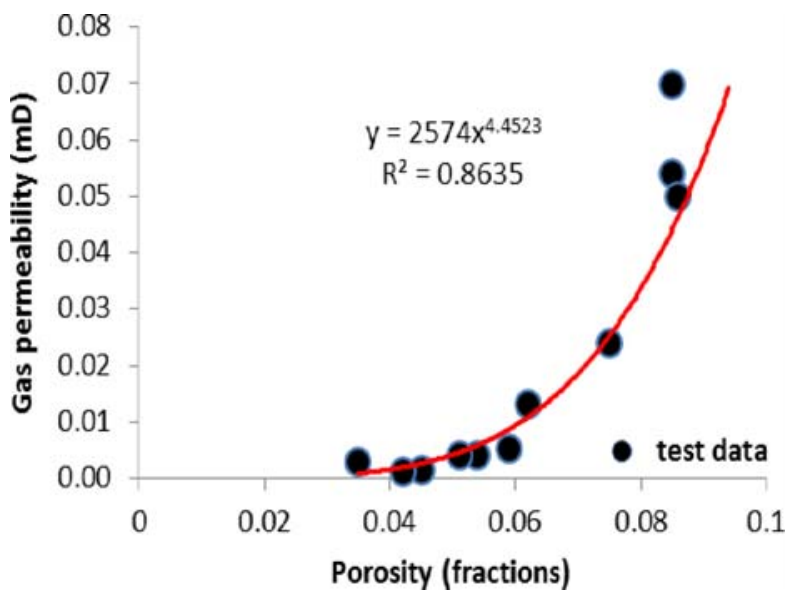

(b)

FIG. 8. PLOT SHOWS THE FITTING CURVES OF THE GAS PERMEABILITY AS A FUNCTION OF SAMPLES EFFECTIVE POROSITY FOR SPECIMENS KFB1 AND KFB2

Mehran University Research Journal of Engineering \& Technology, Volume 36, No. 3, July, 2017 [p-ISSN: 0254-7821, e-ISSN: 2413-7219] 
using existing empirical correlations cannot reproduce the b-factor values for samples of this study. Moreover, the empirical model of Sampath and Keighin [13] provided with an improved correlation which accounts the porosity term (Table 1). The significance of Sampath and Keighin, is that its exponent value is -0.53 is very similar to recent model provided by [7] exponent value which they obtained by theoretical analysis. However, still we were not successful in reproducing the experimental data from the existing models. A introduced an expression to consider samples tortuosity (Table 1). However, it is difficult to know about Sampath and Keighin the tortuosity factor of our samples hence the tortuosity factor for our samples is not known, therefore; it is difficult to derive the implications of Civan et. al. [20] model.

The scatter in data (Fig. 9) could be the samples permeability heterogeneity. Authors [8-25] have proposed that the scatter in between permeability and gas slip factor might be the result of experimental error. In carbonate rock samples having high slippage factor values and high permeability associated with smaller pore radius has also reported by [27]. High slippage values might be existence of pores with greater than average pore size in those samples. Similarly, the samples studied in present study could be result of heterogeneous that is resulted in scatter when plotted against their slip factor, which could be due to experimental error.

Recently,Jones and Owens provided an improved empirical correlation by introducing of porosity term in his model. The results show that model Sampath and Keighin [7] failed in reproduction of experimental gas slippage factor for tight gas sands of Kirthar samples. The two empirical models of tight sands $[11,12]$ resulted in slightly closer estimation of slippage factor values to that of the experimental data compared to the other models. Hence, the scatter within estimated values of permeability using empirical correlations (Fig. 10) is not advantageous, though it is unsafe to use such correlations to predict permeability measurements of tight gas samples of Kirthar fold belt. It would be far better, either b-values should be calculated for each sample separately or a very high gas pore pressure $(>1000$ psi) should be applied to minimize the magnitude of the slippage correction.

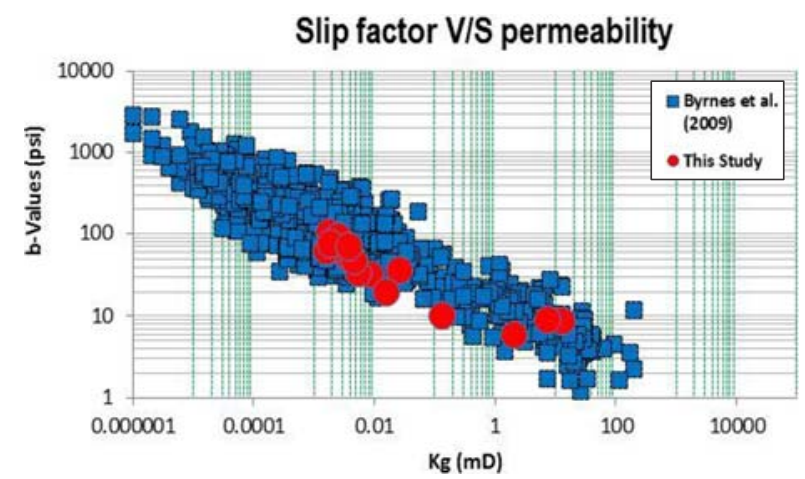

FIG. 10. RELATION BETWEEN GAS SLIPPAGE FACTOR (PSI) AND PERMEABILITY (MD), THE RESULTS ARE FROM THIS STUDY

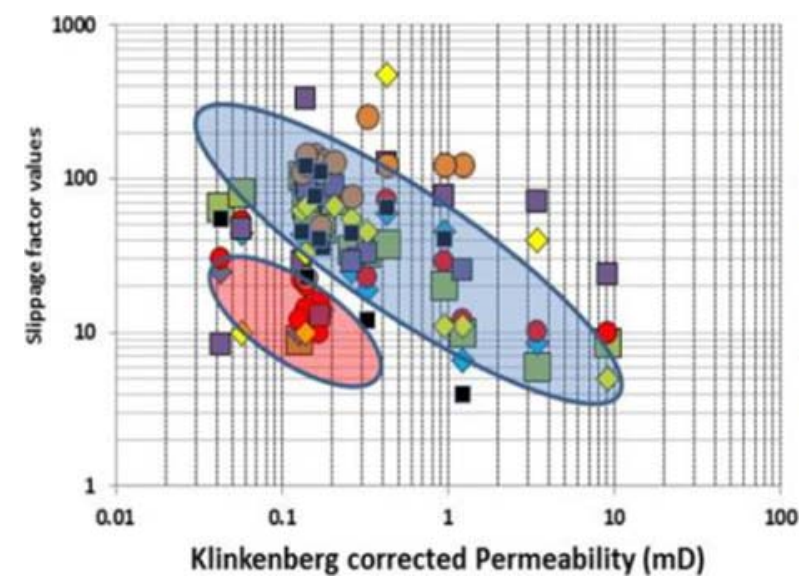

FIG. 9. COMPARISON OF PRESENTING STUDY DATA OF GAS PERMEABILITY AND SLIPPAGE FACTOR DATA WITH THAT OF THE ESTIMATED FROM EXISTING EMPIRICAL CORELATIONS

Mehran University Research Journal of Engineering \& Technology, Volume 36, No. 3, July, 2017 [p-ISSN: 0254-7821, e-ISSN: 2413-7219] 


\section{CONCLUSIONS}

The study was conducted to assess the gas flow characteristics in tight gas sandstones. The tight rock samples permeability, porosity measurements were made under varying pore pressures and over burden stress conditions. The impact of gas slippage on measured permeability of tight sands of Kirthar formations is discussed.The main conclusions drawn from the work is as follows:

(i) The experimental results displays that the plot of gas flow rate and pressures squared difference follows the no-linear trend, this deviation in between gas flow and pressure difference squared provides the nonlinear flow behavior.

(ii) It was also observed from experimental results that gas slippage has a significant effect on tight rocks permeability. As the pore pressure was low, the mean free path of the gas molecules were high and in that situation the slippage effect of gas molecules were considerably high which resulted in high permeability than true permeability of the tight rock samples.

(iii) A relation between permeability and effective porosity was developed and the data fitted with the power law described a good relation.

(iv) The permeability and gas slippage factor correlation was developed based the measured and estimated data, it was found that it is essential to either measure b-values for each sample separately; or otherwise it is recommended to use high gas pore pressures ( $>1000 \mathrm{psi}$ ) so that the Klinkenberg correction becomes negligible for tight gas sandstone reservoirs. (v) By employing a constant overburden stress and using small pore pressure, the Klinkenberg slippage effect was noticeable. As the pore pressure further decreased to certain value, the impact of gas slippage increased by around $40 \%$. Hence, it is essential to take account of the Klinkenberg slippage effect on absolute permeability of tight rocks if the pore pressure is low in such reservoirs and the reservoirs which are sensitive to stress.

\section{ACKNOWLEDGEMENTS}

The authors gratefully acknowledge the support from Prof. Dr. Amanullah Marri, Department of Civil Engineering, NED University of Engineering \& Technology, who helped in preparing this manuscript. Authors are also thankful to their institutes, Mehran University of Engineering \& Technology, Jamshoro, and NED University of Engineering \& Technology, Karachi, Pakistan.

\section{REFERENCE}

[1] Brace, W.F., Walsh, J., and Frangos, W., "Permeability of Granite under High Pressure", Journal of Geophysical Research, Volume 73, No. 6, pp. 2225-2236, 1968.

[2] Jones, S., "A Technique for Faster Pulse-Decay Permeability Measurements in Tight Rocks", Society of Petroleum Engineers Formation Evaluation, Volume 12, No. 1, pp. 19-26, 1997.

[3] Wang, H., Xu, W., and Shao, J.F., "Experimental Researches on Hydro-Mechanical Properties of Altered Rock under Confining Pressures", Rock Mechanics and Rock Engineering, Volume 47, No. 2, pp. 485-493, 2014.

[4] Ziarani, A.S., and Aguilera, R., "Knudsen's Permeability Correction for Tight Porous Media", Transport in Porous Media, Volume 91, No. 1, pp. 239-260, 2012. 
[5] Rushing, J., Newsham, K., Lasswell, P., Cox, J., and Blasingame, T., "Klinkenerg-Corrected Permeability Measurements in Tight Gas Sands: Steady-State Versus Unsteady-State Techniques", Translated by Society of Petroleum Engineers, 2004

[6] Heller, R., Vermylen, J., and Zoback, M., "Experimental Investigation of Matrix Permeability of Gas Shales", American Association of Petroleum Geologists Bulletin, Volume 98, No. 5, pp. 975-995, 2014. "Improved Permeability Prediction Relations for Low Permeability Sands: Rocky Mountain Oil \& Gas Technology Symposium", Society of Petroleum Engineers, 2007.

[15] Rushing, J.A., Newsham, K.E., and Fraassen, K.C.V., "Measurement of the Two-Phase Gas Slippage Phenomenon and its Effect on Gas Relative Permeability in Tight Gas Sands", Society of Petroleum Engineers Annual Technical Conference and Exhibition, 2003.

[16] Byrnes, A.P., Cluff, R.M., and Web, J.C., “Analysis of Critical Permeability, Capillary and Electrical Properties for Mesaverde Tight Gas Sandstones from Western US Basins”, DOE Report DE-FC26-05NT42660, 2009.

[17] Klinkenberg, L., "The Permeability of Porous Media to Liquids and Gases", Drilling and Production Practice, 1941.

[18] Tanikawa, W., and Shimamoto, T., "Klinkenberg Effect for Gas Permeability and its Comparison to Water Permeability for Porous Sedimentary Rocks", Hydro Earth system, Sciety, pp. 1315-1338, 2006.

[19] Zhu, W., Tian, W., and Gao, Y., "Study on Experiment Conditions of Seepage Law of Marine Shale Gas", Natural Gas Geosciety, Volume 26, No. 6, 2015.

[20] Civan, F., Rai, C.S., and Sondergeld, C.H., "Shale-Gas Permeability and Diffusivity Inferred by Improved Formulation of Relevant Retention and Transport Mechanisms", Transport. Porous Media, Volume 86, No. 3, pp. 925e944,2011

[21] McPhee, C.A., and Arthur, K.G., "Klinkenberg Permeability Measurements: Problems and Practical Solutions", Worthington, P.F., and Longeron, D., (Editors), 1991.

[22] Letham, E.A., and Bustin, R.M., "Klinkenberg Gas Slippage Measurements as a Means for Shale Pore Structure Characterization”, Geofluids, Volume 7, 2015.

[23] John, D., Smewing, J., Warburton, TD., Copestake, P., and Haq, N., "Sequence Stratigraphy of the Southern Kirthar Fold Belt and Middle Indus Basin, Pakistan”, Geological SocietySpecial Publications, Volume 195, pp. 273-299, [DOI:10.1144/GSL.SP.2002.195.01.15], London, 2002. 
[24] Shar, A.M., Mahesar, A.A., Chandio, A.D., and Memon, K.R., "Impact of Confining Stress on Permeability of Tight Gas Sands: An Experimental Study", Journal of Petroleum Exploration and Production Technology, [DOI: 10.1007/s13202-016-0296-9], 2016.

[25] Carmichael, S.M., Akhter, S., Bennett1, J.K.M., Fatimi, A., Hosein, K., Jones, R.W., Longacre, M.B., Osborne, M.J., and Tozer, R.S.J., "Geology and Hydrocarbon Potential of the Offshore Indus Basin, Pakistan”, Geological Society of London, Volume 5, pp. 107-116, December, 2016.
[26] Baehr, A.L., and Hult, M.F., "Evaluation of Unsaturated Zone Air Permeability through Pneumatic Tests", Water Resource Research, Volume 27, No. 10, pp. 2605-2617,1991.

[27] Funk, J.J, Choinski, M.C., Saxman, B.B., and Callender, C.A., "Characterization of Carbonate Porosity using Petrophysical Properties and Image Analysis", Middle East Oil Show, Society of Petroleum Engineers, 1989.

Mehran University Research Journal of Engineering \& Technology, Volume 36, No. 3, July, 2017 [p-ISSN: 0254-7821, e-ISSN: 2413-7219] 